\title{
Effect of bio-ethanol on the performance and emission of a biodiesel fueled compression ignition engine
}

\author{
Shrivathsa Nelly Bhat ${ }^{1}$, Shreyas Shenoy ${ }^{2}$ and Dinesha P. ${ }^{3 *}$ \\ ${ }^{1}$ Department of Mechatronics Engineering, Manipal Institute of Technology, Manipal Academy of \\ Higher Education, Manipal, India. \\ ${ }^{2}$ Department of Computer and Communication Engineering, Manipal Institute of Technology, \\ Manipal Academy of Higher Education, Manipal, India. \\ ${ }^{3}$ Department of Mechanical and Manufacturing Engineering, Manipal Institute of Technology, \\ Manipal Academy of Higher Education, Manipal, India.
}

\begin{abstract}
In the present study investigates the effect of bio-ethanol on the performance and emissions of a biodiesel blend fueled compression ignition engine. The experiments are conducted using pongamia biodiesel blend B20 (20\% pongamia biodiesel $+80 \%$ diesel) with $5,7.5$ and $10 \%$ $(\mathrm{v} / \mathrm{v})$ of bio-ethanol on a four stroke single cylinder diesel engine. The tests are conducted at different load conditions. Performance and emissions characteristics are investigated for different bio-ethanol compositions. The results show that the brake thermal efficiency is maximum for B20E7.5 blend with a minimum brake specific fuel consumption. Carbon monoxide emission is minimum for B20E7.5 blend and NOx emission decreases as the bio-ethanol percentage is increased from 5 to $7.5 \%$. The study reveals that $7.5 \%$ bio-ethanol with B20 pongamia biodiesel blend results better performance and emission characteristics.
\end{abstract}

Keywords: Biodiesel; bioethanol; diesel engine; emissions; performance.

\section{Introduction}

Diesel engines produce higher torque at low speeds, which is the key requirement of internal combustion engines. Hence diesel engines are widely used in transportation and industrial sector. Increased use of fossil based fuel in engines cause twin problems viz. energy crisis and environmental degradation. Several attempts being tried by various researchers to overcome these issues [1-3]. Engine modification and fuel modification are the two extensive methods by which these issues can be minimized. Engine modifications include varying the fuel injection parameters such as varying fuel injection pressure and timing $[4,5]$, combustion chamber designs etc. [6]. Fuel modification method is the tuning of the fuel properties to achieve complete combustion [7]. Use of alternative fuels for compression ignition engines are most promising way to reduce environmental degradation

${ }^{*}$ Corresponding author: dinesha.p@manipal.edu 
without negotiating the engine performance. Literature report reveals that there are several alternative fuels being tried in diesel engines [8-9]. These alternative fuels are derived from vegetable seed oils and animal fat. Due to their higher viscosity, straight oils and fats are converted to methyl esters by transesterification process [10]. The methyl ester produced by transesterification is known as biodiesel. Biodiesel has high potential and is a renewable source of energy. Higher viscosity and lower calorific value of neat biodiesel restricts it direct use in compression ignition engines. The physical properties of the biodiesel can be improved by blending with petro-diesel. A blend of $20 \%$ biodiesel with $80 \%$ diesel (B20) results better results in terms of engine performance and exhaust emissions. Researchers reported that the B20 blend of biodiesel of various vegetable oils contribute acceptable performance and emission levels results without any engine modifications [11, 12]. Inbuilt oxygen content of biodiesel helps to achieve more complete combustion, this intern results lower carbon monoxide (CO), unburnt hydrocarbon (HC) and smoke emissions. But biodiesel combustion cause higher emission of oxides of nitrogen (NOx) [13].

NOx emission of internal combustion engine is mainly due to availability of oxygen, temperature of residual gas, resident time etc. NOx emission can be minimized by precombustion and post-combustion treatments $[14,15]$. There are other methods significantly used in reduction of NOx such as use of alcohol as a fuel additive. Due to its higher latent heat of evaporation, lower residual gas temperature is achieved, resulting in lower NOx emission. He et al. [16] reported lower NOx when the ethanol was blended with diesel. Tutak and Bereczky [17] investigated the combustion studies in CI engine when the engine was operated with ethanol-diesel blends. The found lower NOx emission for E85 blend. Use of alcohol as an additive to the fuel blend drastically reduces $\mathrm{CO}, \mathrm{HC}$, smoke and NOx emission. This method is also used in biodiesel fuel operated CI engines. Zhu et al. [18] studied the effect of ethanol-biodiesel fuel on the CI engine emissions. They observed lower NOx and smoke emissions for alcohol blended biodiesel blends. Similar results reported by [19]. But the literature available on bio-ethanol blended biodiesel fuels operations are scanty.

In the present investigation, an attempt has been made to investigate the effect of bioethanol on the performance and emissions of a CI engine when operated using biodieselblend. Pongamia biodiesel B20 blend is selected and three test fuel blends are prepared by adding bio-ethanol in a proportion of $5,7.5$ and $10 \%$ by volume to B20 blend. Performance and emission are analyzed at varying load conditions.

\section{Materials and Methodology}

Pongamia biodiesel is prepared by transesterification process [20]. Bio-ethanol is produced from the cashew apples by fermentation process. The ethanol produced from fermentation process contains small amount of water, it known as raw ethanol. The test fuel blends are made by adding bioethanol to the B20 pongamia biodiesel in a proportion of 5, 7.5 and $10 \%$ by volume. The physical properties are determined as per ASTM standard and tabulated in Table 1.

Table 1: Physical properties of Test fuel blends

\begin{tabular}{|l|l|l|l|}
\hline Property & B20E5 & B20E7.5 & B20E10 \\
\hline Flash point $\left({ }^{\circ} \mathrm{C}\right)$ & 50 & 41 & 43 \\
\hline Fire point $\left({ }^{\circ} \mathrm{C}\right)$ & 55 & 49 & 48 \\
\hline Lower calorific value $(\mathrm{MJ} / \mathrm{kg})$ & 40.89 & 40.49 & 40.09 \\
\hline Kinematic viscosity $(\mathrm{cSt})$ & 3.69 & 3.63 & 4.21 \\
\hline Density $\left(\mathrm{kg} / \mathrm{m}^{3}\right)$ & 840 & 848 & 860 \\
\hline
\end{tabular}




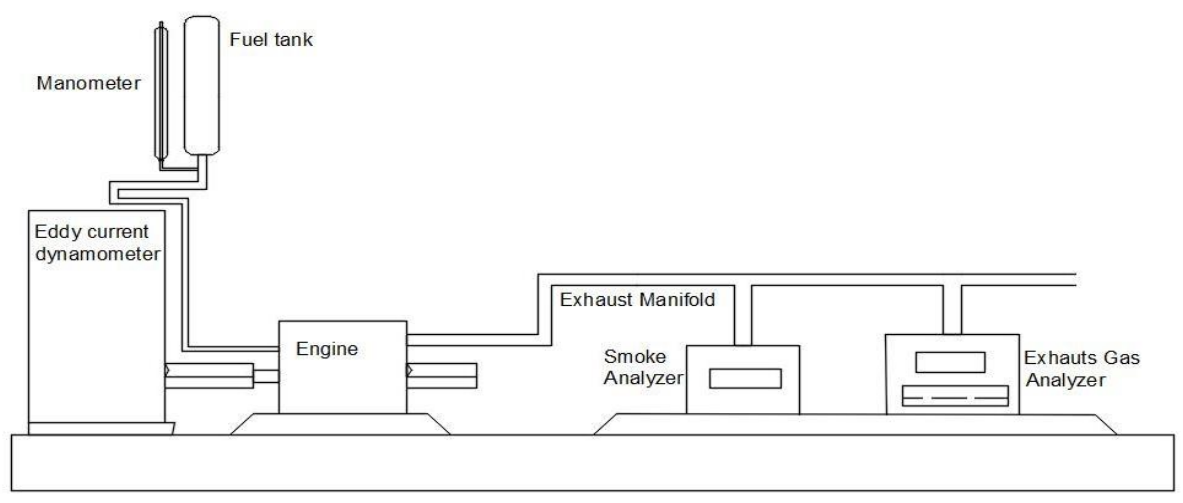

Fig. 1 Schematic representation of the experimental setup

The experiments are conducted on a four stroke single cylinder water cooled diesel engine. Eddy current dynamometer is used to load the engine. Schematic representation of the experimental set up is as shown in Fig. 1. The tests are conducted using three test fuel blends namely B20E5, B20E7.5 and B20E10 at 25, 50, 75 and 100\% of full load of the engine. Emission parameters like carbon monoxide (CO) and NOx are measured using AVL Exhaust gas analyzer. The data pertaining to performance and emissions are recorded for these loads. Performance parameters like brake specific energy consumption (BSEC), brake thermal efficiency (BTE) and emissions like NOx and CO are analyzed and discussed.

\section{Results and discussion}

The engine is run on three different test fuel blends as mentioned above. The performance and engine exhaust emission characteristics are analyzed and discussed.

\subsection{Brake thermal efficiency (BTE)}

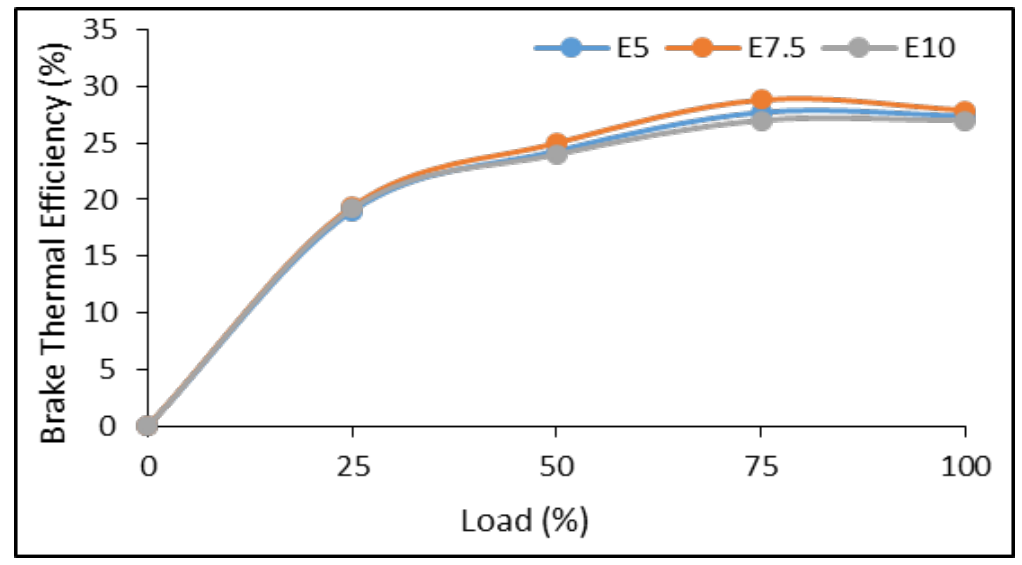

Fig. 2 Brake thermal efficiency verses load 
Fig. 2 shows the relation between BTE with engine load for the test fuels. For all fuel blends, BTE increases as the load increased and reach maximum at $75 \%$ load. BTE is the ratio of brake power to the heat energy supplied. Hence it depends on the calorific value of the fuel and the combustion quality. The fuel blend B20E7.5 has a BTE of $28.8 \%$ at $75 \%$ load, which is maximum among the fuels tested. This may be due to the reason that the inbuilt oxygen content of the fuel favors the combustion and more heat will be generated which intern results higher efficiency. B20E5 and B20E10 result lower BTE due to incomplete combustion and lower caloric value respectively. This is also due to increased BSEC of the fuel blends.

\subsection{Brake Specific Energy Consumption (BSEC)}

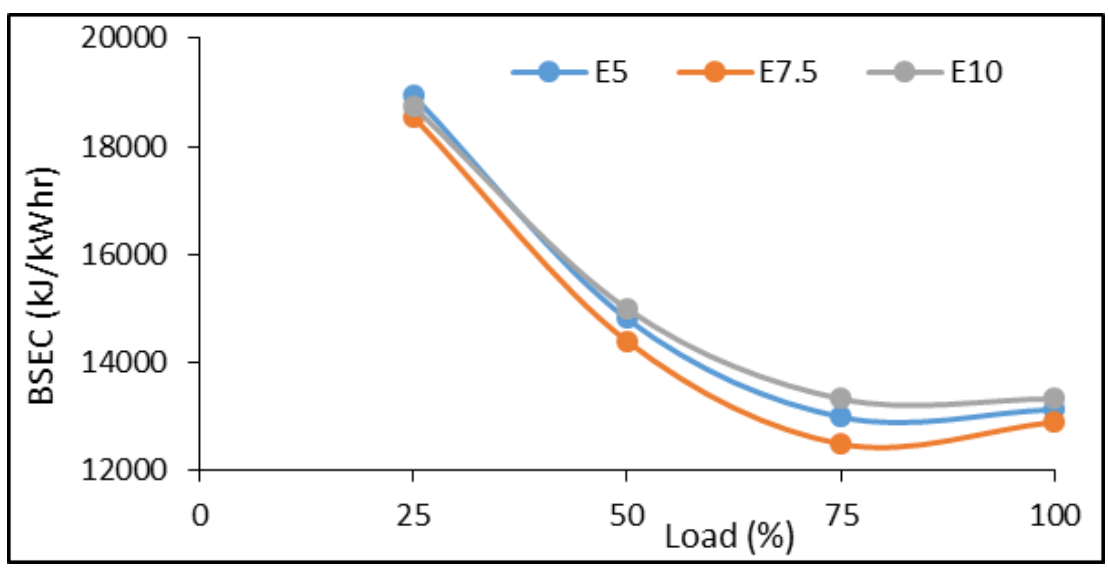

Fig. 3 Brake specific energy consumption verses load

Fig. 3 shows the BSEC for different fuel blends at varying load conditions. BSEC decreases as the load increased and minimum at $75 \%$ load. For the fuel blend B20E7.5, BSEC is minimum compared to other fuels tested. This may be due to the complete utilization of the injected fuel and reduced $\mathrm{CO}$ and unburnt hydrocarbons by more complete combustion. Even the fuel blend B20E5 has extra oxygen content, more complete combustion is not achieved resulting in increased BSEC. In B20E10, more inbuilt oxygen available, but higher BSEC is obtained. Increase in bio-ethanol percentage in the fuel blend increases the inbuilt oxygen content, but the decreases the calorific value. So higher BSEC is obtained for higher bio-ethanol blend.

\subsection{Carbon monoxide emission}

In the Fig. 4, Carbon Monoxide (CO) increases as the load increased for all fuel blends due to rich mixture combustion during higher loads. The reasons for higher $\mathrm{CO}$ emission are too rich fuel-air ratio, lack of oxygen content, combustion duration etc. Use of bioethanol increases the fuel borne oxygen, which intern promotes combustion. The percentage of bioethanol increased from as the fuel-air ratio increased from 5 to $7.5 \%, \mathrm{CO}$ emission decreases. Further increment of bioethanol has no significant benefit results higher CO emission. This may be due to higher latent heat of vaporization, which reduces the rate of combustion. More $\mathrm{CO}$ formation takes place instead of $\mathrm{CO}_{2}$ formation. 


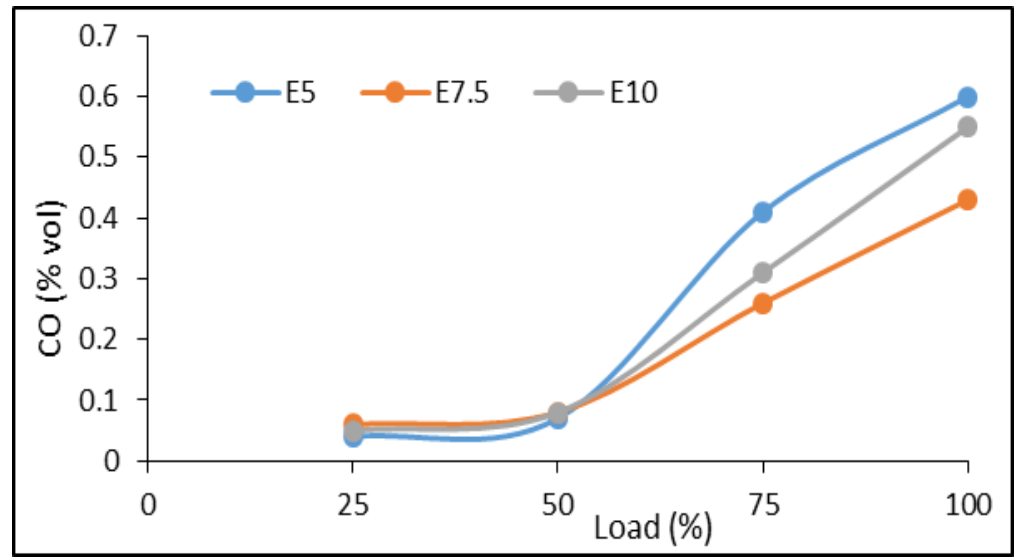

Fig. 4 Carbon monoxide verses load

\subsection{NOx emission}

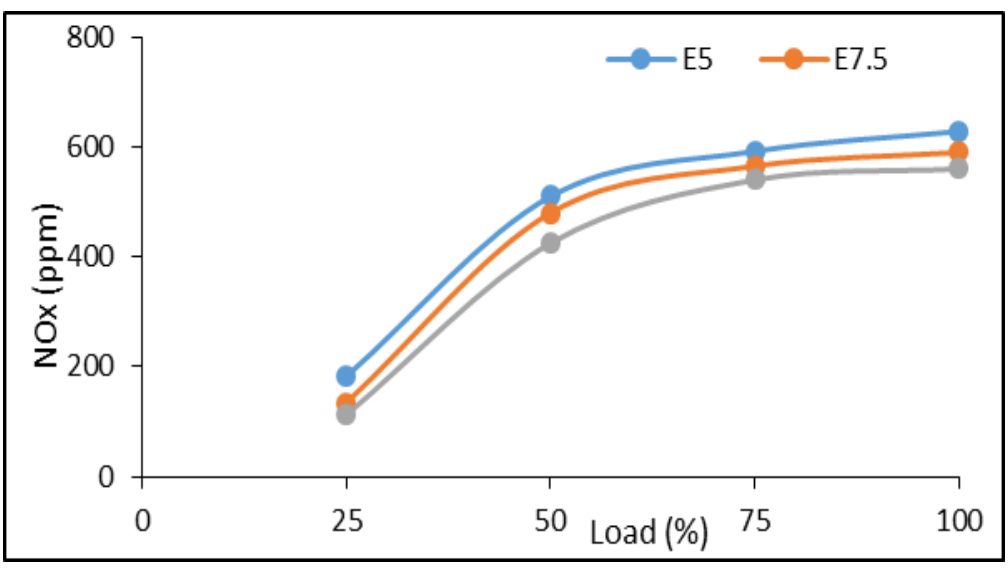

Fig. 5 NOx emission verses load

Fig. 5 shows the variation of NOx emission for various fuel blends at different loads. NOx emission increases as the load increased irrespective of the fuel. There are several reasons for the formation of $\mathrm{NOx}$ in $\mathrm{CI}$ engine. Higher combustion temperature, availability of oxygen and resident time are the key reasons for the formation of NOx. In this study, NOx decreases as the composition of bio-ethanol is increased. Out of three fuel blends tested, B20E5 gives higher NOx. Increase of bio-ethanol increases the oxygen content, but higher latent heat of vaporization of the bio-ethanol decreases the combustion temperature. This helps in reduction of NOx for higher bio-ethanol blends.

\section{Conclusion}

In the present study, the effect of bio-ethanol on the performance and emission of B20 pongamia biodiesel fuel blend. An analysis has been made to optimize the bio-ethanol composition in the blend. From the study, the following conclusions have been made. 
- Bio-ethanol produced from cashew apples by fermentation is a potential fuel additive to the $\mathrm{CI}$ engine operation.

- B20E7.5 has higher BTE compared to other fuel variants tested. It gives a maximum BTE of $28.8 \%$ at $75 \%$ load.

- Lower BSEC of $12500 \mathrm{~kJ} / \mathrm{kWhr}$ is obtained for B20E7.5 compared to B20E5 and B20E10 blends.

- B20E7.5 results lower CO emission of $0.43 \%$ where as B20E5 and B20E10 respectively give 0.55 and $0.6 \%$ at full load condition.

- NOx emission decreases as the percentage of bio-ethanol increased in the blend. A maximum NOx of $628 \mathrm{ppm}$ is obtained for B20E5 blend whereas 590 and 550 ppm are respectively obtained for B20E7.5 and B20E10 blends.

From the study, it can be concluded that a blend having $7.5 \%$ of bio-ethanol has significant benefits in terms of performance and emissions.

\section{References}

1. Rakopoulos DC, Rakopoulos CD, Giakoumis EG, Dimaratos AM, Kyritsis DC. Effects of butanol-diesel fuel blends on the performance and emissions of a high-speed DI diesel engine. Energy Conversion and Management. 2010, 51, pp.1989-97.

2. Yanfeng G, Shenghua L, Hejun G, Tiegang H, Longbao Z. A new diesel oxygenate additive and its effects on engine combustion and emissions. Applied thermal engineering. 2007, 27, pp.202-7.

3. Sorenson SC, Mikkelsen SE. Performance and emissions of a 0.273 liter direct injection diesel engine fuelled with neat dimethyl ether. SAE Technical Paper. 1995.

4. Dinesha P, Mohanan P. A study of the effect of injection pressure on the combustion, performance, and emission characteristics of cardanol biofuel blend fuelled compression ignition engine. Asia-Pacific Journal of Chemical Engineering. 2015, 10, pp.56-64.

5. Alla GA, Soliman HA, Badr OA, Rabbo MA. Effect of injection timing on the performance of a dual fuel engine. Energy conversion and Management. 2002, 43, pp.269-77.

6. Christensen M, Johansson B, Hultqvist A. The effect of combustion chamber geometry on HCCI operation. SAE Technical Paper, 2002.

7. Durbin TD, Collins JR, Norbeck JM, Smith MR. Effects of biodiesel, biodiesel blends, and a synthetic diesel on emissions from light heavy-duty diesel vehicles. Environmental science and Technology. 2000, 34, pp.349-55.

8. Shivakumar, Dinesha P. Use of alternative fuels in compression ignition engines: a review. Biofuels. 2017, DOI: 10.1080/17597269.2017.1329494.

9. Fukuda H, Kondo A, Noda H. Biodiesel fuel production by transesterification of oils. Journal of bioscience and bioengineering. 2001, 92, pp.405-16.

10. Sarin R, Sharma M, Sinharay S, Malhotra RK. Jatropha-palm biodiesel blends: an optimum mix for Asia. Fuel. 2007, 86, pp.1365-71.

11. Nabi MN, Akhter MS, Shahadat MM. Improvement of engine emissions with conventional diesel fuel and diesel-biodiesel blends. Bioresource Technology. 2006, 97, pp.372-8.

12. Lapuerta M, Armas O, Rodriguez-Fernandez J. Effect of biodiesel fuels on diesel engine emissions. Progress in energy and combustion science. 2008, 34, pp.198-223. 
13. Hountalas DT, Mavropoulos GC, Zannis TC, Mamalis SD. Use of water emulsion and intake water injection as NOx reduction techniques for heavy duty diesel engines. SAE Technical Paper. 2006.

14. Koebel M, Elsener M, Kleemann M. Urea-SCR: a promising technique to reduce NO x emissions from automotive diesel engines. Catalysis today. 2000, 59, pp.335-45.

15. He BQ, Shuai SJ, Wang JX, He H. The effect of ethanol blended diesel fuels on emissions from a diesel engine. Atmospheric Environment. 2003, 37, pp.4965-71.

16. Tutak W, Lukács K, Szwaja S, Bereczky Á. Alcohol-diesel fuel combustion in the compression ignition engine. Fuel. 2015, 154, pp.196-206.

17. Zhu L, Cheung CS, Zhang WG, Huang Z. Combustion, performance and emission characteristics of a DI diesel engine fueled with ethanol-biodiesel blends. Fuel. 2011, 90, pp.1743-50.

18. Xing-cai L, Jian-Guang Y, Wu-Gao Z, Zhen H. Effect of cetane number improver on heat release rate and emissions of high speed diesel engine fueled with ethanol-diesel blend fuel. Fuel. 2004, 83, pp.2013-20.

19. Karmee SK, Chandna D, Ravi R, Chadha A. Kinetics of base-catalyzed transesterification of triglycerides from Pongamia oil. Journal of the American Oil Chemists' Society. 2006, 83, pp.873-7. 